\title{
A Model for Selecting Technologies in New Product Development
}

\author{
He-Yau Kang, ${ }^{1}$ Amy H. I. Lee, ${ }^{2}$ Chao-Cheng Chang, ${ }^{1}$ \\ and Mei-Sung Kang ${ }^{3}$ \\ ${ }^{1}$ Department of Industrial Engineering and Management, National Chin-Yi University of Technology, \\ Taichung 411, Taiwan \\ ${ }^{2}$ Department of Technology Management, Chung Hua University, Number 707, Section 2, WuFu Road, \\ Hsinchu 300, Taiwan \\ ${ }^{3}$ Department of Electrical Engineering, Kao Yuan University, Kaohsiung 821, Taiwan
}

Correspondence should be addressed to Amy H. I. Lee, amylee@chu.edu.tw

Received 29 November 2011; Accepted 27 December 2011

Academic Editor: Ricardo Femat

Copyright (c) 2012 He-Yau Kang et al. This is an open access article distributed under the Creative Commons Attribution License, which permits unrestricted use, distribution, and reproduction in any medium, provided the original work is properly cited.

Due to fast changing technologies, shortening product lifecycles, and increased global competition, companies today often need to develop new products continuously and faster. Successful introduction and acceleration of new product development (NPD) is important to obtain competitive advantage for companies. Since technology selection for NPD involves complex decision makings that are critical to the profitability and growth of a company, the selection of the most appropriate technology for a new product requires the use of a robust decision-making framework capable of evaluating several technology candidates based on multiple criteria. This paper presents an integrated model that adopts interpretive structural modeling (ISM) and fuzzy analytic network process (FANP) to evaluate various different available technologies for NPD. The ISM is used to understand the interrelationships among the factors, and the FANP is to facilitate the evaluation process of decision makers under an uncertain environment with interrelated factors. A case study of a flat panel manufacturer is performed to examine the practicality of the proposed model. The results show that the model can be applied for group decision making on the available technology evaluation and selection in new product development.

\section{Introduction}

Products life cycle is shortening continuously under the rapid transition of industrial structure and technology advancement. In order to excel in the competitive markets, new product introduction is important to get new sales and profits. Thus, a company has to keep developing new products to attract customers. In today's highly competitive high-tech 
industry, technology is developed rapidly, and the adoption of new technology is the only means to gain competitive advantage. While there are various technologies that may be used in a new product, different aspects must be considered to determine which technology is most suitable under the circumstances. Thus, a good objective model for evaluating and selecting the right technology to be adopted in the new product is required.

The demands for technology evaluation have increased with the flourishing development of technology licensing, technology transaction, or joint venture on the one hand and the pressing needs of new product introduction on the other hand [1]. In the evaluation of technologies, objective factors, such as cost, profit, revenue and time of completion, and subjective factors, such as flexibility, learning, and capacity increment, all must be considered [2]. Therefore, the problem is a multiple-criteria decision-making (MCDM) in nature. Some MCDM methods are proposed in literature. Punniyamoorthy and Ragavan [2] proposed a deterministic decision making approach, which adopted analytic hierarchy process (AHP) and the Brown-Gibson model (EBG), for technology selection. Since real world knowledge may be fuzzy rather than precise, a useful decision-making model may need to have the ability to handle fuzzy assessments. Chuu [3] proposed a group decision-making model based on fuzzy multiple attributes analysis to assess the suitability of advanced manufacturing technology alternatives, and the fusion of fuzzy assessment data is performed by maximum entropy ordered weighted averaging (MEOWA) operators. Hsu et al. [4] applied fuzzy analytic hierarchy process (FAHP) to find the importance of each criterion in evaluating regenerative technologies. Lee et al. [5] presented an integrated model for evaluating various technologies for NPD by taking into account the benefits, opportunities, costs and risks (BOCR) aspects of different technologies, and adopting interpretive structural modeling (ISM), and fuzzy analytic network process (FANP).

To summarize, the technology selection in new product development (NPD) problem is a fuzzy multiple-criteria and group decision-making problem which involves the consideration of fuzzy assessments and the opinions of multiple experts. Although technology selection is not a new subject in the field of management, no research, in the authors' understanding, has considered the interrelationship of the criteria in the decision making process by incorporating interpretive structural modeling (ISM) and fuzzy analytic network process (FANP). The rest of this paper is organized as follows. Section 2 reviews the related methodologies, and Section 3 develops an integrated model for selecting technologies in NPD. Section 4 examines the model on a flat panel manufacturer in Taiwan for NPD. Some concluding remarks are made in Section 5.

\section{Methodologies}

\subsection{Interpretive Structural Modeling (ISM)}

Interpretive structural modeling (ISM) was first proposed by Warfield to understand complex situations and to put together a course of action for solving a problem [6,7]. It is a process to develop a map of the complex relationships among elements by calculating a binary matrix, called relation matrix [8]. The relation matrix is obtained through individual or group mental models to represent the relations of the elements [8]. A question such as "Does criterion $x_{i}$ affect criterion $x_{j}$ ?" is asked. If the answer is yes, then $\pi_{i j}=1$; otherwise, $\pi_{i j}=0$. A reachability matrix is obtained to consider transitivity, and a final reachability matrix can be calculated under the operators of the Boolean multiplication and addition. The final reachability matrix can reflect the convergence of the relationship among the elements. 


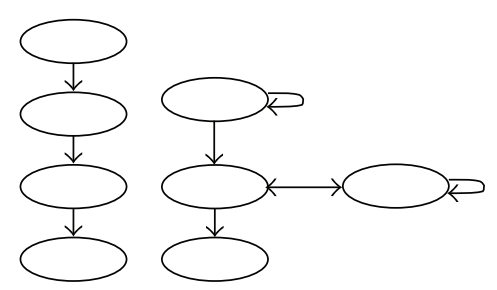

(a) A hierarchy (b) A network

Figure 1: Differences between a hierarchy and a network.

Since its introduction, the ISM has been applied in various fields, including assisting government bodies to prioritize activities, facilitating companies to select projects, and aiding researchers in relevant works. Some recent works that applied ISM are briefly reviewed here. Yang et al. [9] applied the ISM to study the relationships among the subcriteria and used integrated fuzzy MCDM techniques to study the vendor selection problem. Lee et al. [10] employed the ISM to determine the interrelationship among the critical factors for technology transfer of new equipment in high technology industry and applied the FANP to evaluate the technology transfer performance of equipment suppliers. Lee and Lin [11] constructed a systematic framework that incorporates fuzzy Delphi method (FDM), fuzzy interpretive structural modeling (FISM) and FANP into quality function deployment (QFD) for new product development.

\subsection{Fuzzy Analytic Network Process (FANP)}

The AHP is a popular MCDM methodology which has been applied vastly in various fields, for example, in Punniyamoorthy and Ragavan [2], Hsu et al. [4], and Chai and Sun [12]. The analytic network process (ANP) approach is a generalization of the AHP [13]. The ANP approach replaces hierarchies with networks, in which the relationships between levels are not easily represented as higher or lower, dominated, or being dominated, directly or indirectly [14]. Figure 1 shows the structural difference between a hierarchy and a network, in which a node represents a component (or cluster) with elements inside it, and an arc denotes the interaction between two components. The direction of an arc indicates dependence, a twoway arrow represents the interdependencies between two components, and a loop signifies the inner dependence of elements within a component [15].

The fuzzy set theory can be incorporated into the ANP to tackle the uncertain and imprecise pairwise comparison in the conventional ANP, and it is called FANP. The procedure for the FANP can be summarized as follows $[10,16]$.

(1) Decompose the problem into a network.

(2) Prepare a questionnaire based on the constructed network and ask experts to fill out the questionnaire.

(3) Transform the scores of pairwise comparison into linguistic variables and aggregate the results of the experts' questionnaires.

(4) Obtain crisp numbers by defuzzying the synthetic triangular fuzzy numbers.

(5) Calculate the maximum eigenvalues and eigenvectors.

(6) Check the consistency property of the matrix. 
(7) Form an unweighted supermatrix. An example of a supermatrix is as follows [14]:

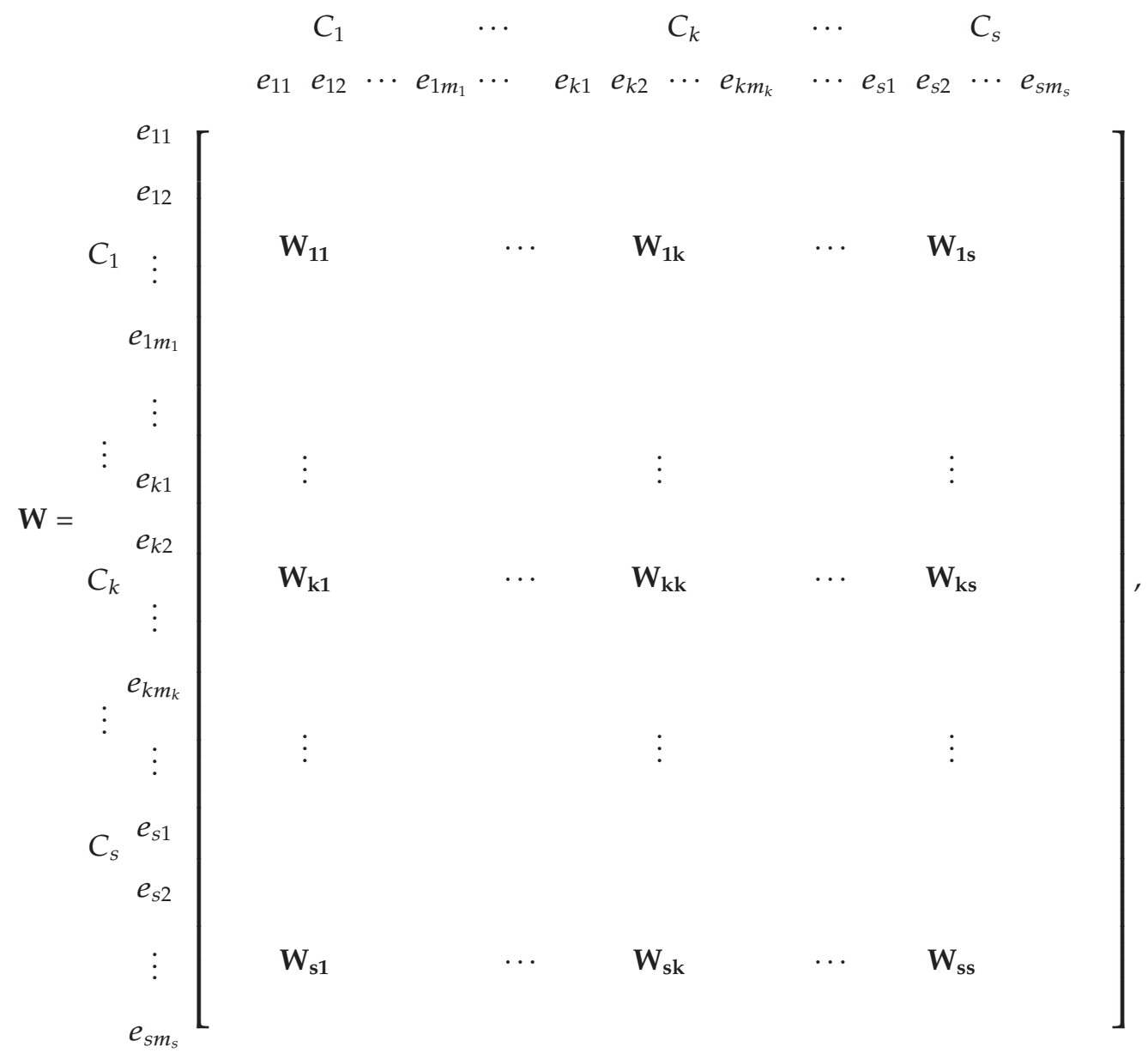

where the components are $C_{k}, k=1, \ldots, s$, and each component $k$ has $m_{k}$ elements, denoted by $e_{k 1}, e_{k 2}, \ldots, e_{k m_{k}}$. The eigenvectors obtained in Step (5) are grouped and located in appropriate positions in the supermatrix based on the flow of influences.

(8) Form a weighted supermatrix.

(9) Obtain the limit supermatrix and the priority weights of the alternatives.

\section{A Model for Evaluating Technologies}

In this study, we construct a technology evaluation model that incorporates FANP and ISM. The proposed steps are as follows.

(1) Form a committee of experts to define the technology evaluation problem in the flat panel industry. Through literature review and interview with experts, a network 
for evaluation is constructed. The network should comprise the goal, criteria, subcriteria and alternatives.

(2) Use ISM to determine the inter-relationship among the subcriteria, with the same upper-level criterion:

(2.1) prepare the relation matrix to construct the relationships of the subcriteria with the same upper-level criterion. Let the subcriteria under criterion $c$ as $x_{i}^{c}, i=1,2,3, \ldots, n ; x_{i}^{c}$ is the $i$ th subcriterion, $x_{j}^{c}$ is the $j$ th subcriterion, and $\pi_{i j}^{c}$ is the relation between $i$ th and $j$ th subcriteria. If $x_{i}^{c}$ influences $x_{j}^{c}$, then $\pi_{i j}^{c}=1$; otherwise, $\pi_{i j}^{c}=0$. If $x_{j}^{c}$ influences $x_{i}^{c}$, then $\pi_{j i}^{c}=1$; otherwise, $\pi_{j i}^{c}=0$. In the case that there are several experts, a questionnaire is prepared to ask the contextual relationship between any two subcriteria, and the associated direction of the relation. A relation matrix which shows the contextual relationship among the subcriteria is established for each expert. The geometric mean of experts' opinions on the relationship between a pair of subcriteria is calculated. A threshold value is used to determine whether the two subcriteria are dependent or not $[9,16]$. If the geometric mean value between two subcriteria, that is, $\bar{\pi}_{i j}^{c}$, in the mean relation matrix is higher than the threshold value, $x_{j}^{c}$ is deemed reachable from $x_{i}^{c}$, and we let $\bar{\pi}_{i j}=1[9,16]$. Establish relation matrix which shows the contextual relationship among the factors. The relation matrix $\mathbf{D}_{c}$ is presented as follows:

$$
\begin{aligned}
& \begin{array}{llll}
x_{1}^{c} & x_{2}^{c} & \cdots & x_{n}^{c}
\end{array} \\
& \begin{array}{r}
\mathbf{D}_{c}= \\
x_{1}^{c} \\
\quad \\
\quad x_{n}^{c} \\
\vdots
\end{array}\left[\begin{array}{cccc}
0 & \bar{\pi}_{12}^{c} & \cdots & \bar{\pi}_{1 n}^{c} \\
\bar{\pi}_{21}^{c} & 0 & \ldots & \bar{\pi}_{2 n}^{c} \\
\vdots & \vdots & 0 & \vdots \\
\bar{\pi}_{n 1}^{c} & \bar{\pi}_{n 2}^{c} & \cdots & 0
\end{array}\right], \quad i=1,2, \ldots, n ; j=1,2, \ldots, n,
\end{aligned}
$$

(2.2) develop reachability matrix and check for transitivity. The initial reachability matrix $\mathbf{M}_{c}$ is calculated by adding $\mathbf{D}_{c}$ with the unit matrix $\mathbf{I}$ :

$$
\mathbf{M}_{c}=\mathbf{D}_{c}+\mathbf{I},
$$

(2.3) develop final reachability matrix $\mathbf{M}_{c}^{*}$. The transitivity of the contextual relation means that if subcriterion $x_{i}^{c}$ is related to $x_{j}^{c}$ and $x_{j}^{c}$ is related to $x_{p}^{c}$, then $x_{i}^{c}$ is necessarily related to $x_{p}^{c}$. Under the operators of the Boolean multiplication and addition (i.e., $1 \times 0=0 \times 1=0,1+0=0+1=1$ ), a convergence can be met

$$
\mathbf{M}_{c}^{*}=\mathbf{M}_{c}^{b}-\mathbf{M}_{c}^{b+1}, \quad b>1,
$$




$$
\begin{aligned}
& \begin{array}{llll}
x_{1}^{c} & x_{2}^{c} & \cdots & x_{n}^{c}
\end{array} \\
& \mathbf{M}_{c}^{*}=\begin{array}{c}
x_{1}^{c} \\
x_{2}^{c} \\
\vdots \\
x_{n}^{c}
\end{array}\left[\begin{array}{cccc}
\pi_{11}^{c^{*}} & \pi_{12}^{c^{*}} & \cdots & \pi_{1 n}^{c^{*}} \\
\pi_{21}^{c^{*}} & \pi_{22}^{c^{*}} & \cdots & \pi_{2 n}^{c^{*}} \\
\vdots & \vdots & \vdots & \vdots \\
\pi_{n 1}^{c^{*}} & \pi_{n 2}^{c^{*}} & \cdots & \pi_{n n}^{c^{*}}
\end{array}\right], \quad i=1,2, \ldots, n ; j=1,2, \ldots, n,
\end{aligned}
$$

where $\pi_{i j}^{c^{*}}$ denotes the relation between the $i$ th sub-criterion and the $j$ th subcriterion.

(3) Plot the network structures for the subcriteria with the same upper-level criterion.

(4) Employ questionnaire and collect experts' opinions. Experts are asked to pairwise compare the elements in a questionnaire. The scores of pairwise comparison of each part of the questionnaire from each expert are transformed into linguistic variables by the transformation concept listed in Table 1 . The fuzzy positive reciprocal matrix can be defined as $[17,18]$ :

$$
\tilde{\mathrm{A}}^{k}=\left[\tilde{a}_{i j}\right]^{k}
$$

where $\tilde{\mathrm{A}}^{k}$ is the positive reciprocal matrix of expert $k, \tilde{a}_{i j}$ is the relative importance between decision elements $i$ and $j$, and $\tilde{a}_{i j}=1$, for all $i=j$ and $\tilde{a}_{i j}=1 / \tilde{a}_{j i}$, for all $i, j=1,2, \ldots, n$.

(5) Build aggregated pairwise comparison matrices. Apply geometric average approach to aggregate experts' responses, and prepare fuzzy aggregated pairwise comparison matrices. Let there be $k$ experts, every pairwise comparison between two criteria has $k$ positive reciprocal triangular fuzzy numbers. Employ geometric average approach to aggregate multiple experts' responses, and the aggregate fuzzy positive reciprocal matrix is

$$
\widetilde{\mathrm{A}}^{*}=\left[\tilde{a}_{i j}^{*}\right]
$$

where $\tilde{a}_{i j}^{*}=\left(\tilde{a}_{i j}^{1} \otimes \tilde{a}_{i j}^{2} \otimes \cdots \otimes \tilde{a}_{i j}^{k}\right)^{1 / k}$.

(6) Form aggregated pairwise comparison matrices by defuzzifying fuzzy aggregated pairwise comparison matrices. Synthetic triangular fuzzy numbers $\tilde{a}_{i j}^{*}=\left(x_{i j}, y_{i j}\right.$, $z_{i j}$ ) can be transformed into crisp numbers using a defuzzification method, such as the Centroid method:

$$
a_{i j}^{*}=\frac{\left(x_{i j}+y_{i j}+z_{i j}\right)}{3}, \quad \forall i, j=1,2, \ldots, n
$$


Table 1: Membership functions of triangular fuzzy numbers.

\begin{tabular}{lccc}
\hline Fuzzy number & Linguistic variable & $\begin{array}{c}\text { Positive triangular } \\
\text { fuzzy numbers }\end{array}$ & $\begin{array}{c}\text { Positive reciprocal } \\
\text { triangular fuzzy } \\
\text { numbers }\end{array}$ \\
\hline$\widetilde{1}$ & Equally important & $(1,1,3)$ & $(1 / 3,1,1)$ \\
$\widetilde{3}$ & Moderately important & $(1,3,5)$ & $(1 / 5,1 / 3,1)$ \\
$\widetilde{5}$ & Important & $(3,5,7)$ & $(1 / 7,1 / 5,1 / 3)$ \\
$\widetilde{7}$ & Very important & $(5,7,9)$ & $(1 / 9,1 / 7,1 / 5)$ \\
$\widetilde{9}$ & Extremely important & $(7,9,9)$ & $(1 / 9,1 / 9,1 / 7)$ \\
\hline
\end{tabular}

(7) Calculate priority vectors and examine the consistency of the aggregated pairwise comparison matrices. Calculate the maximum eigenvalue, $\lambda_{\max }$, and the eigenvector, $w$, for the matrix [19]:

$$
\mathbf{A}^{*} \cdot w=\lambda_{\max } \cdot w .
$$

The consistency test [19] is performed by calculating the consistency index (CI) and consistency ratio (CR):

$$
\begin{gathered}
\mathrm{CI}=\frac{\lambda_{\max }-n}{n-1}, \\
\mathrm{CR}=\frac{\mathrm{CI}}{\mathrm{RI}},
\end{gathered}
$$

where $n$ is the number of items being compared in the matrix, and RI is random index [19]. If CR is less than 0.1, the experts' judgments are consistent. If the consistency test is not passed, the part of the questionnaire must be done again.

(8) Form an un-weighted supermatrix. The priority vectors are entered in the appropriate columns of a matrix, called an un-weighted supermatrix, as shown in Figure 2.

(9) Form a weighted supermatrix. A weighted super-matirx is prepared so that each column in the supermatrix sums to unity. When there is interdependence among clusters in a network, some columns of a supermatrix sum to more than one. The supermatrix must be transformed first to make it stochastic. The procedure can be found in Saaty [13] and Lee et al. [16].

(10) Calculate the limit supermatrix. The limit supermatrix is obtained by raising the weighted supermatrix to the power of $2 p+1$ so a stable supermatrix is reached.

(11) Rank the alternatives. The priority weights of alternatives are shown in the alternative-to-goal block in the limit supermatrix.

\section{A Case Study}

With an increasing global demand of information technology, flat panels with low weight, slender profile, low power consumption, high resolution, high brightness and low radiance 


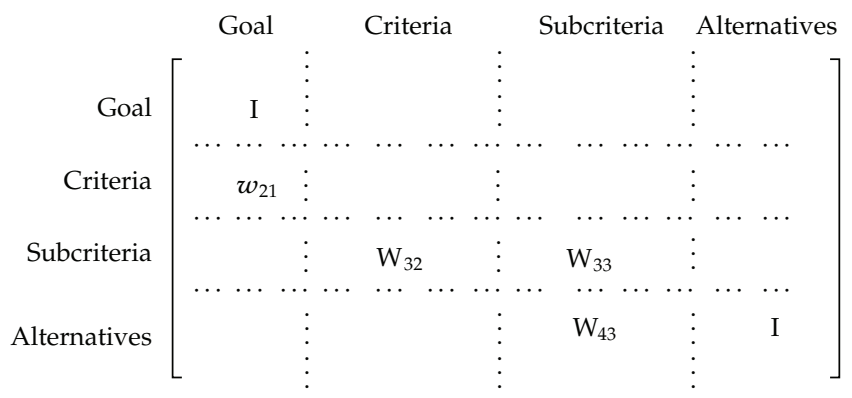

Figure 2: Un-weighted supermatrix.

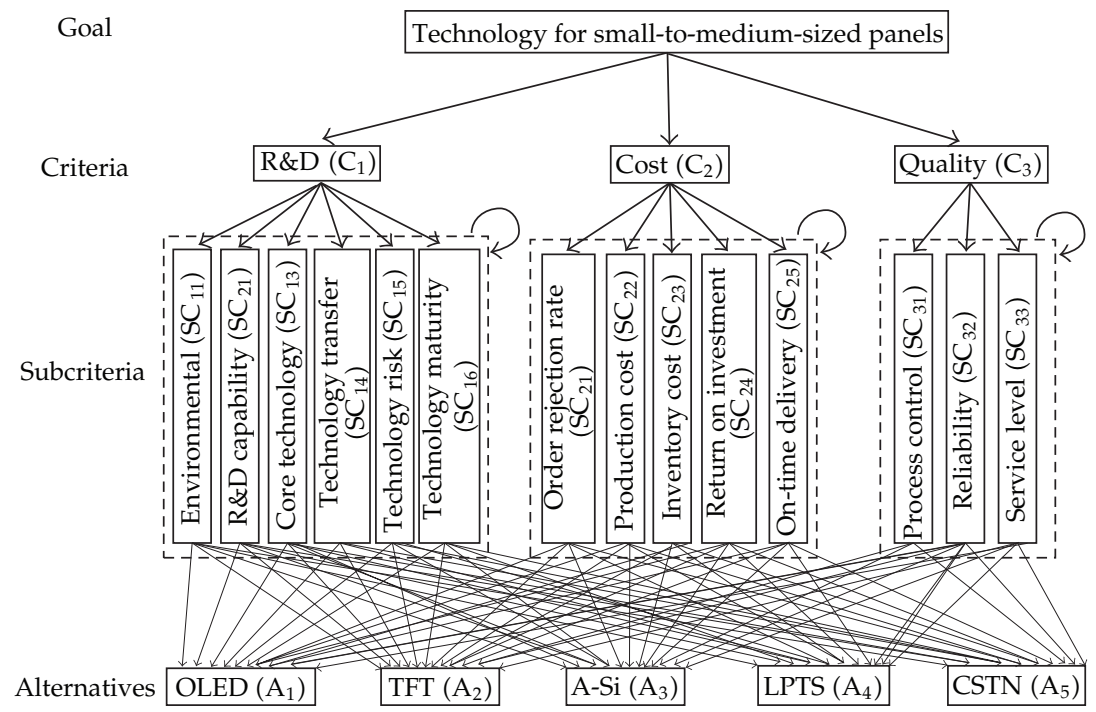

Figure 3: The network for selecting the most suitable technology.

are demanded by end-users. While manufacturers enter and expand their production capacity, the production value of the flat panel industry increases tremendously, and an extremely competitive and cost-cutting war is foreseeable. Therefore, manufacturers, in order to survive in this global competitive market, need to develop products with advanced technology.

Through literature review and interview with five experts in the company, the most important criteria for selecting a technology for producing panels are $R \& D$, cost and quality. Under each criterion, there are subcriteria, which are interrelated. The technologies, which are the most probable to be adopted and which are considered currently in making smallto-medium-sized panels, are organic light-emitting diode (OLED), thin film transistor (TFT), amorphous silicon (a-Si), low temperature poly silicon (LTPS), and color supertwist nematic (CSTN). The network for the problem is constructed in Figure 3.

ISM is applied next to determine the interrelationship among subcriteria under each upper-level criterion. The five experts are asked to fill out a questionnaire to determine the contextual relationship between any two subcriteria, and the associated direction of the relation. The experts' opinions on the relationship between each pair of subcriteria are 


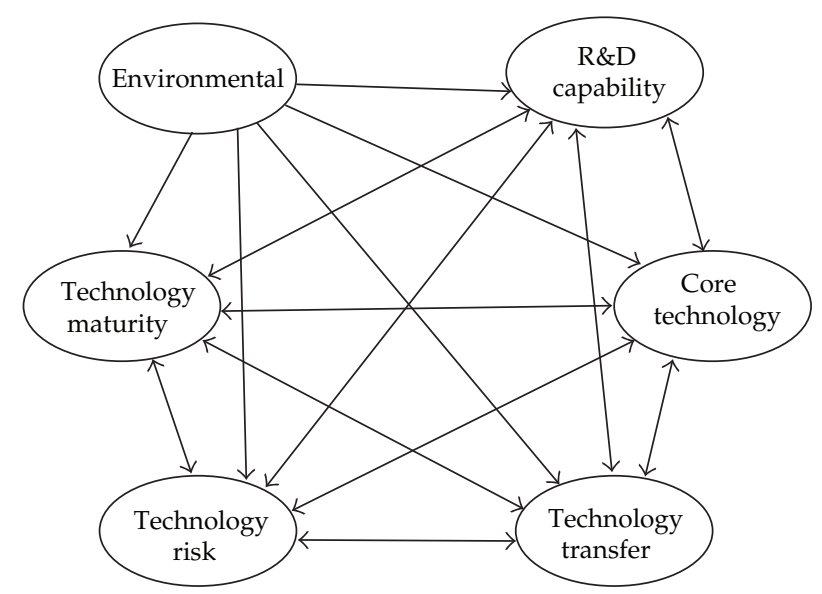

Figure 4: Interrelationship among subcriteria under R\&D.

synthesized using the geometric mean method. A threshold value of 0.5 is used to determine whether the two subcriteria are dependent or not $[9,16]$. For example, the integrated relation matrix among subcriteria under the criterion R\&D is as shown in Table 2.

The initial reachability matrix $\mathbf{M}_{1}$ for subcriteria under $R \& D$ is

$$
\mathbf{M}_{1}=\mathbf{D}_{1}+\mathbf{I}=\left[\begin{array}{llllll}
0 & 1 & 1 & 0 & 0 & 0 \\
0 & 0 & 1 & 0 & 0 & 0 \\
0 & 1 & 0 & 1 & 1 & 1 \\
0 & 0 & 1 & 0 & 1 & 0 \\
0 & 0 & 0 & 1 & 0 & 1 \\
0 & 1 & 1 & 1 & 1 & 0
\end{array}\right]+\left[\begin{array}{llllll}
1 & 0 & 0 & 0 & 0 & 0 \\
0 & 1 & 0 & 0 & 0 & 0 \\
0 & 0 & 1 & 0 & 0 & 0 \\
0 & 0 & 0 & 1 & 0 & 0 \\
0 & 0 & 0 & 0 & 1 & 0 \\
0 & 0 & 0 & 0 & 0 & 1
\end{array}\right]=\left[\begin{array}{llllll}
1 & 1 & 1 & 0 & 0 & 0 \\
0 & 1 & 1 & 0 & 0 & 0 \\
0 & 1 & 1 & 1 & 1 & 1 \\
0 & 0 & 1 & 1 & 1 & 0 \\
0 & 0 & 0 & 1 & 0 & 1 \\
0 & 1 & 1 & 1 & 1 & 1
\end{array}\right] .
$$

The final reachability matrix $\mathbf{M}_{1}^{*}$ for subcriteria under $R \& D$ is

$$
\mathbf{M}_{1}^{*}=\mathbf{M}_{1}^{2}=\left[\begin{array}{llllll}
1 & 1 & 1 & 1 & 1 & 1 \\
0 & 1 & 1 & 1 & 1 & 1 \\
0 & 1 & 1 & 1 & 1 & 1 \\
0 & 1 & 1 & 1 & 1 & 1 \\
0 & 1 & 1 & 1 & 1 & 1 \\
0 & 1 & 1 & 1 & 1 & 1
\end{array}\right]
$$

Based on $\mathbf{M}_{1}^{*}$, the inter-relationship among the six subcriteria under the criterion $R \& D$ can be depicted as in Figure 4. The same procedure can be carried out for determining the inter-relationship among the subcriteria under the criterion cost and the criterion quality.

Based on the network in Figures 3 and 4, a pairwise comparison questionnaire is prepared, and the experts are asked to do the questionnaire. The opinions are aggregated, and 
Table 2: Relation matrix $D_{1}$ among subcriteria under R\&D.

\begin{tabular}{lcccccc}
\hline & $\mathrm{SC}_{11}$ & $\mathrm{SC}_{12}$ & $\mathrm{SC}_{13}$ & $\mathrm{SC}_{14}$ & $\mathrm{SC}_{15}$ & $\mathrm{SC}_{16}$ \\
\hline $\mathrm{SC}_{11}$ & 0 & 1 & 1 & 0 & 0 & 0 \\
$\mathrm{SC}_{12}$ & 0 & 0 & 1 & 0 & 0 & 0 \\
$\mathrm{SC}_{13}$ & 0 & 1 & 0 & 1 & 1 & 1 \\
$\mathrm{SC}_{14}$ & 0 & 0 & 1 & 0 & 1 & 0 \\
$\mathrm{SC}_{15}$ & 0 & 0 & 0 & 1 & 0 & 1 \\
$\mathrm{SC}_{16}$ & 0 & 1 & 1 & 1 & 1 & 0 \\
\hline
\end{tabular}

aggregated pairwise comparison matrices are prepared. Use the criteria as an example, the pairwise comparison between $R \& D$ and cost by the five experts are " $\widetilde{5}^{-1}$ ", “ $\widetilde{5}-1$ ", “ $\widetilde{3}$ ", “ $\widetilde{5}$ ", and “ $\widetilde{3}$ ". The fuzzy numbers are $(1 / 7,1 / 5,1 / 3),(1 / 7,1 / 5,1 / 3),(1,3,5),(3,5,7)$, and $(1,3,5)$. The aggregated triangular fuzzy number is $(0.572,1.125,1.811)\left(=(1 / 7 \times 1 / 7 \times 1 \times 3 \times 1)^{1 / 5},(1 / 5 \times\right.$ $\left.1 / 5 \times 3 \times 5 \times 3)^{1 / 5},(1 / 3 \times 1 / 3 \times 5 \times 7 \times 5)^{1 / 5}\right)$. The fuzzy aggregated pairwise comparison matrix for the criteria is

$$
\widetilde{\mathbf{W}}_{21}=\begin{array}{ccc}
\text { R\&D } & \text { Cost } & \text { Quality } \\
\text { Cost } \\
\text { Quality }
\end{array}\left[\begin{array}{ccc}
(1,1,1) & (0.572,1.125,1.81) & (0.491,0.75,1.267) \\
(0.552,0.889,1.748) & (1,1,1) & (0.903,1.38,3.16) \\
(0.789,1.332,2.036) & (0.316,0.725,1.108) & (1,1,1)
\end{array}\right]
$$

The Centroid method is applied next to prepare a defuzzified comparison matrix. For example, with the synthetic triangular fuzzy number for the comparison between R\&D and cost of $(0.572,1.125,1.81)$, the defuzzified comparison between R\&D and cost is 1.169 . The defuzzified aggregated pairwise comparison matrix is:

$$
\begin{aligned}
& \text { R\&D Cost Quality } \\
& \mathbf{W}_{\mathbf{2 1}}=\begin{array}{c}
\mathrm{R} \& \mathrm{D} \\
\text { Cost } \\
\text { Quality }
\end{array}\left[\begin{array}{ccc}
1 & 1.169 & 0.836 \\
0.855 & 1 & 1.814 \\
1.196 & 0.551 & 1
\end{array}\right] \text {. }
\end{aligned}
$$

The priority vector and $\lambda_{\max }$ of the defuzzified aggregated pairwise comparison matrix for criteria are calculated:

$$
w_{21}=\begin{gathered}
\mathrm{R} \& \mathrm{D} \\
\text { Cost }
\end{gathered}\left[\begin{array}{l}
0.32853 \\
0.38336 \\
0.28812
\end{array}\right], \quad \lambda_{\max }=3.1048
$$


The consistency test is performed by calculating the consistency index (CI) and consistency ratio $(\mathrm{CR})$ :

$$
\begin{gathered}
C I=\frac{\lambda_{\max }-n}{n-1}=\frac{3.1084-3}{3-1}=0.0542, \\
C R=\frac{C I}{R I}=\frac{0.0542}{0.58}=0.0935 .
\end{gathered}
$$

Since CR is less than 0.1 , the experts' judgment is consistent. If the consistency test fails, the experts are required to fill out the specific part of the questionnaire again until a consensus is met.

The relative importance of the $\mathrm{R} \& \mathrm{D}$, cost, and quality is $0.32853,0.38336$, and 0.28812 , respectively. Based on the questionnaires, a similar procedure is done to calculate the priority vector for the importance of subcriteria under each criterion, the inter-relationship among subcriteria under each criterion, and the performance of alternatives with respect to each subcriterion. These priorities are entered into the designated places in a supermatrix, as shown in Table 3. To make the matrix stochastic, a weighted supermatrix is formed, as shown in Table 4. Finally, by taking the weighted supermatrix to a large power, a limit supermatrix is obtained, as shown in Table 5. The priorities of the alternatives can be seen from the alternative-togoal block of the limit supermatrix. The ranking and the priorities of the alternatives are TFT (0.3176), LTPS (0.1959), a-Si (0.1790), OLED (0.1672), and CSTN (0.1403). To summarize, the company, with the consideration of various importance of criteria and subcriteria, should select TFT as the most suitable technology for its new product.

A detailed evaluation of the expected performance of the five technologies under different criteria and subcriteria is shown in Table 6. For example, under criterion R\&D $\left(C_{1}\right)$, TFT $\left(A_{2}\right)$ ranks the first, with a priority of 0.33027 , followed by LTPS $\left(A_{4}\right)$, a-Si $\left(A_{3}\right)$, $\operatorname{OLED}\left(\mathrm{A}_{1}\right), \operatorname{CSTN}\left(\mathrm{A}_{5}\right)$ with priorities of $0.19837,0.17506,0.17198$ and 0.12432 , respectively. Under sub-criterion environmental $\left(\mathrm{SC}_{11}\right)$, TFT $\left(\mathrm{A}_{2}\right)$ also has the highest score, 0.28242 , while the scores for OLED $\left(\mathrm{A}_{1}\right)$, a-Si $\left(\mathrm{A}_{3}\right)$, LTPS $\left(\mathrm{A}_{4}\right)$, and $\operatorname{CSTN}\left(\mathrm{A}_{5}\right)$ are $0.23462,0.16523$, 0.17641 , and 0.14131 , respectively. In fact, TFT $\left(\mathrm{A}_{2}\right)$ performs the best under all criteria and all subcriteria. However, note that TFT $\left(\mathrm{A}_{2}\right)$ is not always the best alternative under every sub-criterion initially. This can be seen from the alternative-to-sub-criteria block of the unweighted supermatrix in Table 3. It ranks the second, second, third, second, and third under the subcriteria environmental $\left(\mathrm{SC}_{11}\right)$, technology transfer $\left(\mathrm{SC}_{14}\right)$, technology risk $\left(\mathrm{SC}_{15}\right)$, inventory cost $\left(\mathrm{SC}_{23}\right)$, and return on investment $\left(\mathrm{SC}_{24}\right)$, respectively. Its ranking becomes the best under all subcriteria after the inter-relationship of the subcriteria is considered, that is, when a convergence is reached in the limit supermatrix. Since TFT $\left(A_{2}\right)$ has an integrated largest priority of 0.31764 and it performs the best under all criteria and subcriteria, it has a better overall expected performance than other technologies. Thus, TFT $\left(A_{2}\right)$ should be selected under the current circumstances.

A company should understand its underlying reasons in selecting a new technology. As calculated before and also shown in Table 7, the priorities of the three criteria, R\&D, cost and quality are $0.32853,0.38336$ and 0.28812 , respectively. Criterion cost ranks first, followed by R\&D and quality. This means that cost-related issues are the primary concerns for the company. However, $R \& D$ factors are also very important since the company is in a high-tech industry and NPD is essential for the long-term survival of the company. The priorities of 


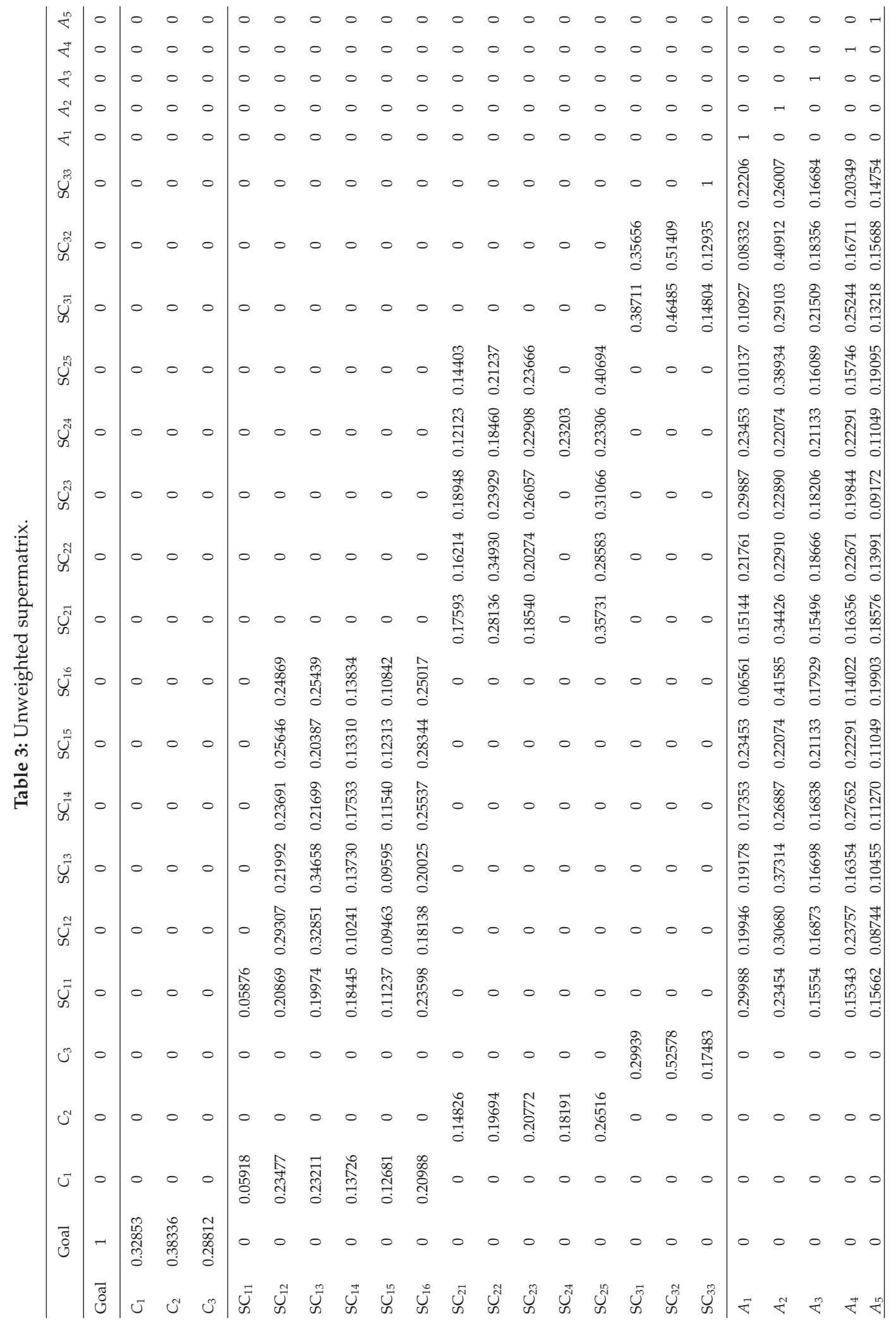




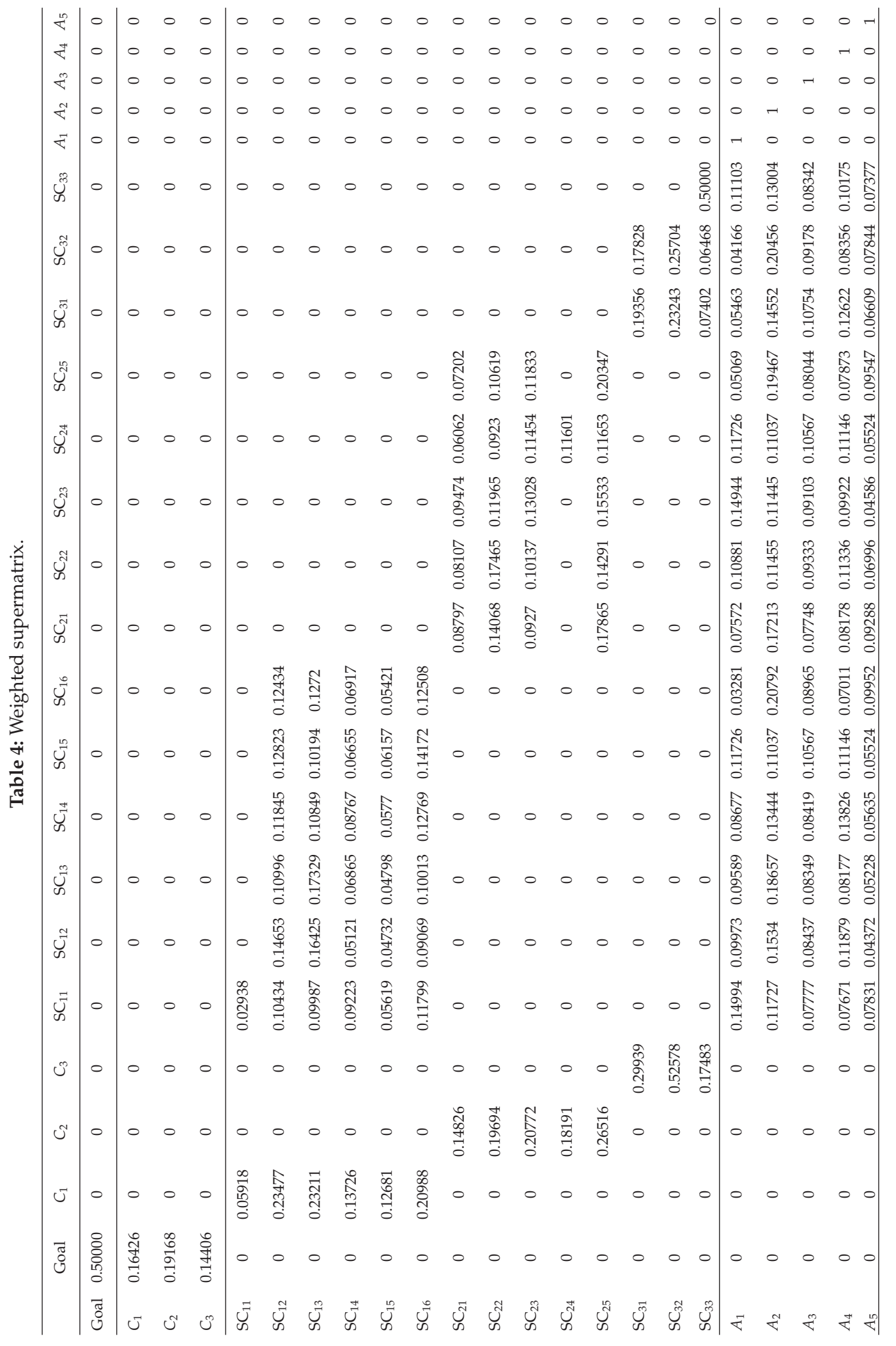


Table 6: Expected performance of the five technologies.

\begin{tabular}{lccccc}
\hline Criteria/subcriteria & OLED $\left(A_{1}\right)$ & TFT $\left(A_{2}\right)$ & a-Si $\left(A_{3}\right)$ & LTPS $\left(A_{4}\right)$ & CSTN $\left(A_{5}\right)$ \\
\hline R\&D $\left(C_{1}\right)$ & 0.17198 & 0.33027 & 0.17506 & 0.19837 & 0.12432 \\
Environmental $\left(\mathrm{SC}_{11}\right)$ & 0.23462 & 0.28242 & 0.16523 & 0.17641 & 0.14131 \\
R\&D capability $\left(\mathrm{SC}_{12}\right)$ & 0.18505 & 0.32158 & 0.17161 & 0.21785 & 0.10392 \\
Core technology $\left(\mathrm{SC}_{13}\right)$ & 0.18025 & 0.35519 & 0.17080 & 0.18039 & 0.11337 \\
Technology transfer $\left(\mathrm{SC}_{14}\right)$ & 0.16937 & 0.30158 & 0.17192 & 0.23828 & 0.11885 \\
Technology risk $\left(\mathrm{SC}_{15}\right)$ & 0.19931 & 0.27831 & 0.19356 & 0.21058 & 0.11823 \\
Technology maturity $\left(\mathrm{SC}_{16}\right)$ & 0.11574 & 0.37608 & 0.17727 & 0.16920 & 0.16171 \\
\hline Cost $\left(C_{2}\right)$ & 0.19197 & 0.29391 & 0.17560 & 0.18973 & 0.14879 \\
Order rejection rate $\left(\mathrm{SC}_{21}\right)$ & 0.16679 & 0.32460 & 0.16312 & 0.17472 & 0.17077 \\
Production cost $\left(\mathrm{SC}_{22}\right)$ & 0.20265 & 0.26359 & 0.17954 & 0.20770 & 0.14652 \\
Inventory cost $\left(\mathrm{SC}_{23}\right)$ & 0.24320 & 0.26542 & 0.17677 & 0.19221 & 0.12239 \\
Return on investment $\left(\mathrm{SC}_{24}\right)$ & 0.21546 & 0.25494 & 0.19425 & 0.20718 & 0.12817 \\
On-time delivery $\left(\mathrm{SC}_{25}\right)$ & 0.14186 & 0.34831 & 0.16594 & 0.17088 & 0.17302 \\
\hline Quality $\left(C_{3}\right)$ & 0.12870 & 0.33480 & 0.18791 & 0.20127 & 0.14732 \\
Process control $\left(\mathrm{SC}_{31}\right)$ & 0.11802 & 0.31175 & 0.20246 & 0.22851 & 0.13925 \\
Reliability $\left(\mathrm{SC}_{32}\right)$ & 0.10373 & 0.37278 & 0.18664 & 0.18501 & 0.15184 \\
Service level $\left(\mathrm{SC}_{33}\right)$ & 0.22206 & 0.26007 & 0.16684 & 0.20349 & 0.14754 \\
\hline
\end{tabular}

Table 7: Priorities of factors.

\begin{tabular}{llc}
\hline Criteria & Subcriteria & Priorities \\
\hline & Environmental $\left(\mathrm{SC}_{11}\right)$ & 0.05918 \\
$\mathrm{R} \& \mathrm{D}\left(\mathrm{C}_{1}\right)$ & R\&D capability $\left(\mathrm{SC}_{12}\right)$ & 0.23477 \\
$(0.32853)$ & Core technology $\left(\mathrm{SC}_{13}\right)$ & 0.23211 \\
& Technology transfer $\left(\mathrm{SC}_{14}\right)$ & 0.13726 \\
& Technology risk $\left(\mathrm{SC}_{15}\right)$ & 0.12681 \\
& Technology maturity $\left(\mathrm{SC}_{16}\right)$ & 0.20988 \\
\hline & Order rejection rate $\left(\mathrm{SC}_{21}\right)$ & 0.14826 \\
Cost $\left(C_{2}\right)$ & Production cost $\left(\mathrm{SC}_{22}\right)$ & 0.19694 \\
$(0.38336)$ & Inventory cost $\left(\mathrm{SC}_{23}\right)$ & 0.20772 \\
& Return on investment $\left(\mathrm{SC}_{24}\right)$ & 0.18191 \\
& On-time delivery $\left(\mathrm{SC}_{25}\right)$ & 0.26516 \\
\hline \multirow{2}{*}{ Quality $\left(\mathrm{C}_{3}\right)$} & Process control $\left(\mathrm{SC}_{31}\right)$ & 0.29939 \\
$(0.28812)$ & Reliability $\left(\mathrm{SC}_{32}\right)$ & 0.52578 \\
& Service level $\left(\mathrm{SC}_{33}\right)$ & 0.17483 \\
\hline
\end{tabular}

the subcriteria are also listed in Table 7. It is not appropriate to study the priorities of the subcriteria with the consideration of interdependence due to the fact that there are transient subcriteria and sink subcriteria in the network [13]. Therefore, the priorities of the subcriteria, with the assumption of independence among the elements, are examined here. Under the criterion $R \& D, R \& D$ capability $\left(S_{12}\right)$, with a priority of 0.23477 , is the most important sub-criterion, followed by core technology $\left(\mathrm{SC}_{13}\right)$ with a priority of 0.23211 and technology maturity $\left(\mathrm{SC}_{16}\right)$ with a priority of 0.20988 . This means that under the aspect of $\mathrm{R} \& \mathrm{D}$ the 
company concerns the most about whether it has adequate R\&D capability to develop the panel with the alternative technology, whether the technology is a core technology of the company, and whether the technology is a matured technology in the industry. Under the criterion cost, on-time delivery $\left(\mathrm{SC}_{25}\right)$ is the most important with a priority of 0.26516 . Inventory cost $\left(\mathrm{SC}_{23}\right)$ and production cost $\left(\mathrm{SC}_{22}\right)$ ranked the second and the third with priorities of 0.20772 and 0.19694 , respectively. Because the company's operation is basically make-to-order, on-time delivery is very important to meet the fundamental demand of customers. With the obsoleteness issue of high-tech products and relatively high production cost, the company must emphasize on cost reduction. Under the criterion quality, reliability $\left(\mathrm{SC}_{32}\right)$ is the most important sub-criterion, with a priority of 0.52578 . This implies that the selected technology alternative should be able to provide reliable products to customers. In conclusion, the company should base on the priorities of the criteria and subcriteria in evaluating and selecting the technology for NPD.

\section{Conclusions}

Companies often need to develop new products in order to survive in the market. Since different technologies are appropriate in different setting under different time frame and for specific purposes, understanding the environment in selecting the most appropriate technology can be a complex decision with many variables to consider. In this paper, an integrated model for selecting the most appropriate technology is developed. The ISM is applied to understand the inter-relationships among the factors, and the ANP is used to calculate the priorities of the technologies. A case study is used to verify the practicality of the proposed model. The model also provides a good evaluation of the factors on technology evaluation, and these factors can be a reference for the company or other companies in the industry to make performance evaluation of technologies that can be adopted in designing a new product. The proposed model can be tailored and applied for a manufacturer which needs to make the technology selection decision.

\section{Acknowledgment}

This work was supported in part by the National Science Council in Taiwan under Grant NSC 98-2410-H-167-008-MY3.

\section{References}

[1] S.-W. Hung and S.-C. Tseng, "A new framework integrating environmental effects into technology evaluation," Journal of Business Ethics, vol. 95, no. 4, pp. 543-556, 2010.

[2] M. Punniyamoorthy and P. V. Ragavan, "A strategic decision model for the justification of technology selection," The International Journal of Advanced Manufacturing Technology, vol. 21, no. 1, pp. 72-78, 2003.

[3] S.-J. Chuu, "Group decision-making model using fuzzy multiple attributes analysis for the evaluation of advanced manufacturing technology," Fuzzy Sets and Systems, vol. 160, no. 5, pp. 586-602, 2009.

[4] Y.-L. Hsu, C.-H. Lee, and V. B. Kreng, "The application of Fuzzy Delphi Method and Fuzzy AHP in lubricant regenerative technology selection," Expert Systems with Applications, vol. 37, no. 1, pp. 419-425, 2010.

[5] A. H. I. Lee, H.-Y. Kang, and C.-C. Chang, "An integrated interpretive structural modeling-fuzzy analytic network process-benefits, opportunities, costs and risks model for selecting technologies," International Journal of Information Technology \& Decision Making, vol. 10, no. 5, pp. 843-871, 2011.

[6] J. N. Warfield, "Developing interconnection matrices in structural modeling," IEEE Transactions on Systems, Man, and Cybernetics, vol. 4, no. 1, pp. 81-87, 1974. 
[7] J. N. Warfield, "Toward interpretation of complex structural models," IEEE Transactions on Systems, Man, and Cybernetics, vol. 4, no. 5, pp. 405-417, 1974.

[8] J.-J. Huang, G.-H. Tzeng, and C.-S. Ong, "Multidimensional data in multidimensional scaling using the analytic network process," Pattern Recognition Letters, vol. 26, no. 6, pp. 755-767, 2005.

[9] J. L. Yang, H. N. Chiu, G.-H. Tzeng, and R. H. Yeh, "Vendor selection by integrated fuzzy MCDM techniques with independent and interdependent relationships," Information Sciences, vol. 178, no. 21, pp. 4166-4183, 2008.

[10] A. H. I. Lee, C.-Y. Lin, S.-R. Wang, and Y.-M. Tu, "The construction of a comprehensive model for production strategy evaluation," Fuzzy Optimization and Decision Making, vol. 9, no. 2, pp. 187-217, 2010.

[11] A. H. I. Lee and C.-Y. Lin, "An integrated fuzzy QFD framework for new product development," Flexible Services and Manufacturing Journal, vol. 23, no. 1, pp. 26-47, 2011.

[12] L. Chai and T. Sun, "The design of LQG controller for active suspension based on analytic hierarchy process," Mathematical Problems in Engineering, vol. 2010, Article ID 701951, 19 pages, 2010.

[13] T. L. Saaty, Decision Making with Dependence and Feedback: The Analytic Network Process, RWS Publications, Pittsburgh, Pa, USA, 1996.

[14] S.-H. Chung, A. H. I. Lee, and W. L. Pearn, "Analytic network process (ANP) approach for product mix planning in semiconductor fabricator," International Journal of Production Economics, vol. 96, no. 1, pp. 15-36, 2005.

[15] S.-H. Chung, A. H. I. Lee, and W. L. Pearn, "Product mix optimization for semiconductor manufacturing based on AHP and ANP analysis," International Journal of Advanced Manufacturing Technology, vol. 25, no. 11-12, pp. 1144-1156, 2005.

[16] A. H. I. Lee, W.-M. Wang, and T.-Y. Lin, "An evaluation framework for technology transfer of new equipment in high technology industry," Technological Forecasting and Social Change, vol. 77, no. 1, pp. $135-150,2010$.

[17] J. J. Buckley, “Fuzzy hierarchical analysis," Fuzzy Sets and Systems, vol. 17, no. 3, pp. 233-247, 1985.

[18] H.-Y. Kang and A. H. I. Lee, "Priority mix planning for semiconductor fabrication by fuzzy AHP ranking," Expert Systems with Applications, vol. 32, no. 2, pp. 560-570, 2007.

[19] T. L. Saaty, The Analytic Hierarchy Process, McGraw-Hill, New York, NY, USA, 1980. 


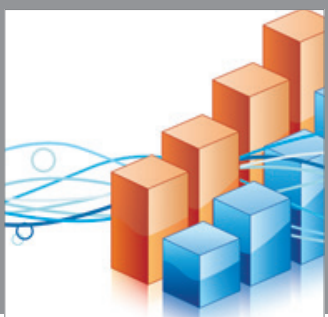

Advances in

Operations Research

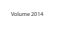

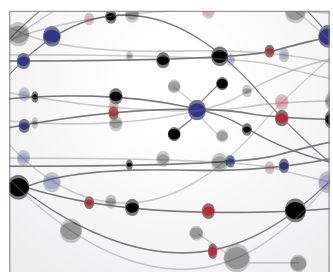

\section{The Scientific} World Journal
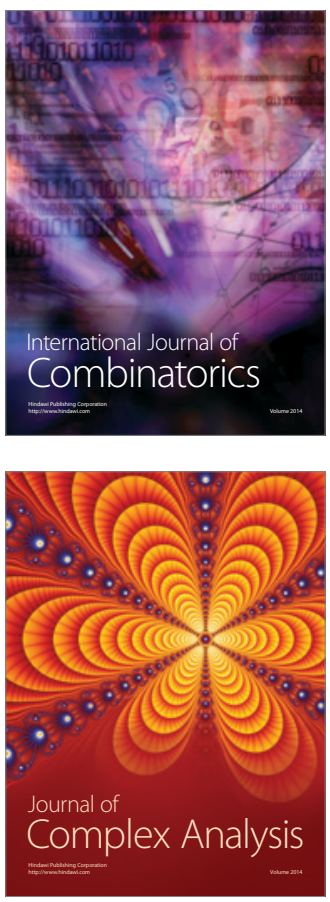

International Journal of

Mathematics and

Mathematical

Sciences
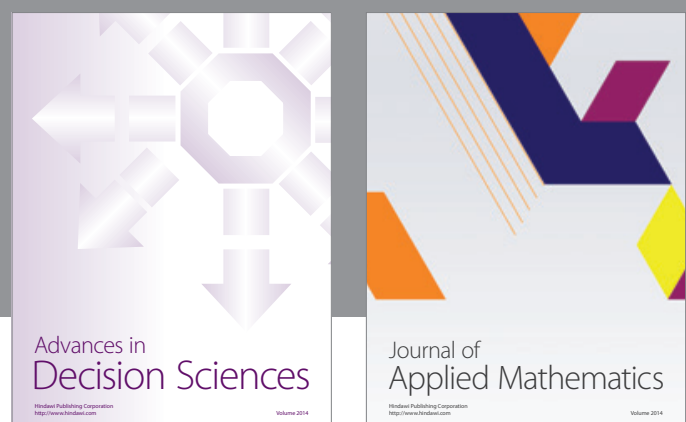

Journal of

Applied Mathematics
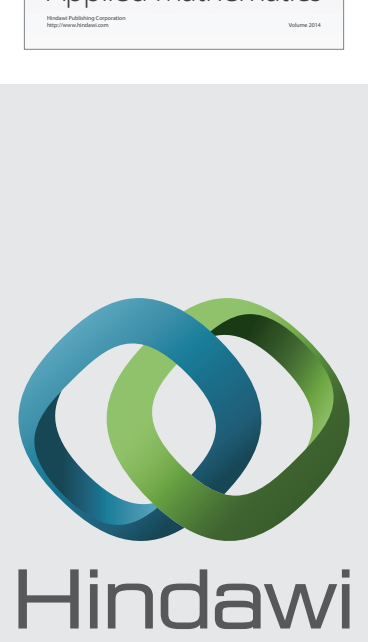

Submit your manuscripts at http://www.hindawi.com
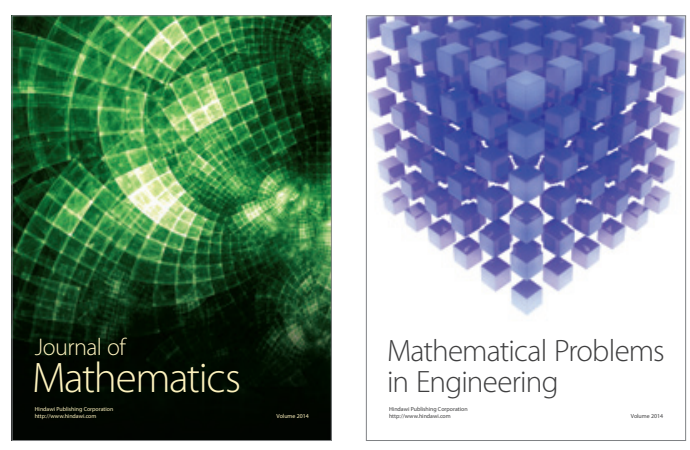

Mathematical Problems in Engineering
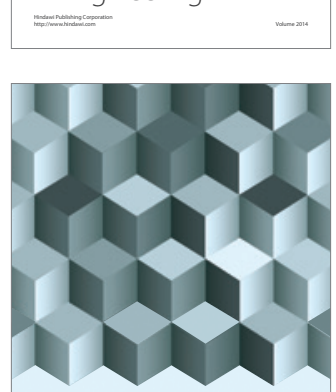

Journal of

Function Spaces
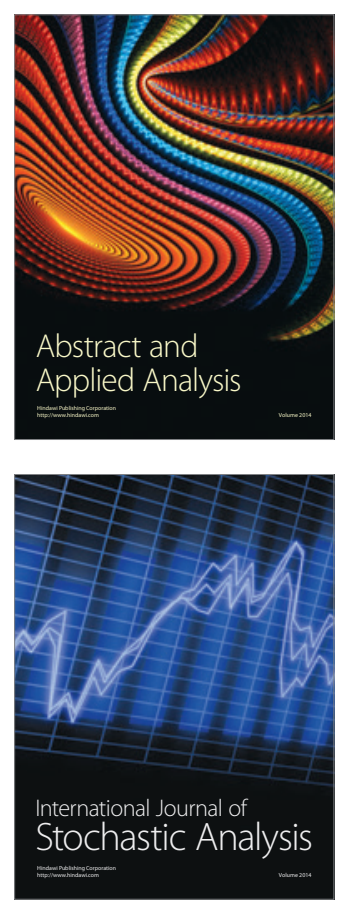

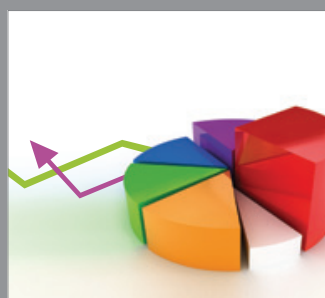

ournal of

Probability and Statistics

Promensencen
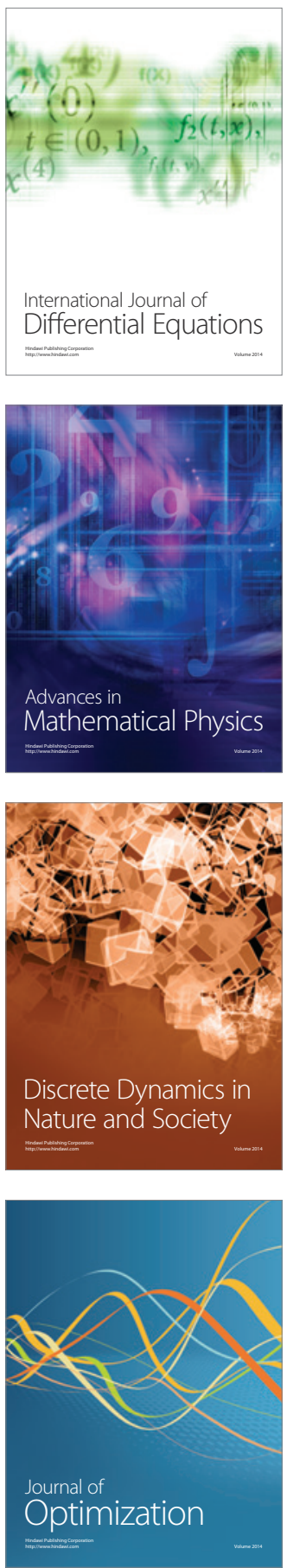